\title{
B cell epitope designing and their docking with ACE2 receptor for peptide based subunit vaccine against SARS-CoV-2: An antigen informatics approach
}

\author{
Aditya Agrawal ${ }^{1}$, Mamta Pathak ${ }^{1}$, Shailesh Patel ${ }^{1}$, and Vishal Rai ${ }^{1}$ \\ ${ }^{1}$ ICAR-Indian Veterinary Research Institute
}

May 5, 2020

\begin{abstract}
Emerging pathogens have been an eternal threat to mankind. In a series of pandemics caused by notorious coronaviruses, a newly emerged virus is creating panic among world population. Originating in late December, 2019 from Wuhan, China, the SARS-CoV-2 is spreading its terror throughout the world. The virus is rapidly transmitted due to unavailability of effective theranostics. In this study, multiple sequence alignment of SARS-CoV-2 spike protein was done and four novel inserts were found in comparison to SARS-CoV. Using computational informatics tool viz. IEDB B-cell epitopes prediction tool, B-cell immunogenic epitopes of SARS-CoV-2 spike protein was predicted. Five novel potent epitopes i.e. '71SGTNGTKRFDN81, 247SYLTPG252, 634RVYST638, 675QTQTNSPRRARSV687 and 1054QSAPH1058 were selected as antigenic determinants and their docking with the 3D structure of ACE2 receptor was delineated. The quantum of information generated by this study will prove beneficial for development of effective therapeutics, diagnostics and multiepitopic vaccines to combat this ongoing menace.
\end{abstract}

\section{Hosted file}

Coronavirus Bioinformatics Proteins..25.03.2020.doc available at https://authorea.com/users/ 306087/articles/436839-b-cell-epitope-designing-and-their-docking-with-ace2-receptorfor-peptide-based-subunit-vaccine-against-sars-cov-2-an-antigen-informatics-approach

\section{Hosted file}

Figures Proteins 25.03.20.docx available at https://authorea.com/users/306087/articles/ 436839-b-cell-epitope-designing-and-their-docking-with-ace2-receptor-for-peptide-basedsubunit-vaccine-against-sars-cov-2-an-antigen-informatics-approach 